\title{
Article \\ The Association between Symmetrical or Asymmetrical High-Arched Feet and Muscle Fatigue in Young Women
}

\author{
Renata Woźniacka ${ }^{1, *} \mathbb{*}$, tukasz Oleksy $2,3,4 \oplus$, Agnieszka Jankowicz-Szymańska ${ }^{5}\left(\mathbb{D}\right.$, Anna Mika ${ }^{6}$, \\ Renata Kielnar ${ }^{7}$ and Artur Stolarczyk ${ }^{2}$ (I)
}

1 Institute of Applied Sciences, University of Physical Education in Krakow, al. Jana Pawła II 78, 31-571 Kraków, Poland

2 Orthopaedic and Rehabilitation Department, Medical University of Warsaw, 02-091 Warsaw, Poland; loleksy@oleksy-fizjoterapia.pl (Ł.O.); drstolarczyk@gmail.com (A.S.)

3 Physiotherapy and Sports Centre, Rzeszow University of Technology, 35-082 Rzeszów, Poland

4 Oleksy Medical \& Sports Sciences, 37-100 Łańcut, Poland

5 Institute of Health Sciences, State Higher Vocational School in Tarnow, ul. Mickiewicza 8, 33-100 Tarnów, Poland; jankowiczszymanska@gmail.com

6 Institute of Clinical Rehabilitation, University of Physical Education in Kraków, al. Jana Pawła II 78, 31-571 Kraków, Poland; anna.mika@awf.krakow.pl

7 Institute of Health Sciences, Medical College of Rzeszów University, 35-315 Rzeszów, Poland kielnarrenata@o2.pl

* Correspondence: renata.wozniacka@awf.krakow.pl

\section{check for}

updates

Citation: Woźniacka, R.; Oleksy, Ł.; Jankowicz-Szymańska, A.; Mika, A.; Kielnar, R.; Stolarczyk, A. The Association between Symmetrical or Asymmetrical High-Arched Feet and Muscle Fatigue in Young Women. Symmetry 2022, 14, 52. https:// doi.org/10.3390/sym14010052

Academic Editors:

Giorgio Vallortigara and

Kazuhiko Sawada

Received: 21 November 2021

Accepted: 22 December 2021

Published: 1 January 2022

Publisher's Note: MDPI stays neutral with regard to jurisdictional claims in published maps and institutional affiliations.

Copyright: (C) 2022 by the authors. Licensee MDPI, Basel, Switzerland. This article is an open access article distributed under the terms and conditions of the Creative Commons Attribution (CC BY) license (https:// creativecommons.org/licenses/by/ $4.0 /)$.
Abstract: The foot arches are responsible for proper foot loading, optimal force distribution, and transmission throughout the soft tissues. Since the foot arch is an elastic structure, able to adapt to forces transmitted by the foot, it was reported that low arch is related to excessive foot pronation, while high arched foot is more rigid and inflexible. Therefore, it is also probable, that foot arch alterations may change the force transmission via myofascial chains. The objective of this study was to evaluate the effect of symmetrical and asymmetrical excessive feet arching on muscle fatigue in the distal body parts such as the lower limbs, trunk, and head. Seventy-seven women ( $25.15 \pm 5.97$ years old, $62 \pm 10 \mathrm{~kg}, 167 \pm 4 \mathrm{~cm}$ ) were assigned to three groups according to the foot arch index (Group 1-both feet with normal arch, Group 2-one foot with normal arch and the other high-arched, Group 3-both feet with high-arch). The bioelectrical activity of the right and left hamstrings muscles, erector spine, masseter, and temporalis muscle was recorded by sEMG during the isometric contraction lasting for $60 \mathrm{~s}$. The stable intensity of the muscle isometric contraction was kept for all the time during the measurement. Mean frequency difference (\%), slope $(\mathrm{Hz})$, and intercept $(\mathrm{Hz})$ values were calculated for muscle fatigue evaluation. No differences were observed in fatigue variables for all evaluated muscles between the right and left side in women with symmetrical foot arches, but in the group with asymmetric foot arches, the higher muscle fatigue on the normal-arched side compared to the high-arched side was noted. Significantly greater values of the semitendinosus-semimembranosus muscle frequency difference was observed on the normal-arched side compared to the high-arched side $(p=0.04 ; \mathrm{ES}=0.52 ;-29.5 \pm 9.1 \%$ vs. $-24.9 \pm 8.4 \%$ ). In the group with asymmetric foot arches, a significantly higher value of lumbar erector spinae muscle frequency slope $(p=0.01$; $\mathrm{ES}=1.32 ;-0.20 \pm 0.04 \mathrm{~Hz}$ vs. $-0.14 \pm 0.05 \mathrm{~Hz})$ and frequency difference ( $p=0.04 ; \mathrm{ES}=0.92 ;-7.8 \pm 3.1 \%$ vs. $-4.8 \pm 3.4 \%$ ) were observed on the high-arched foot side compared to the side with normal foot arching. The thoracic erector spine muscle frequency slope was significantly larger in women with asymmetrical arches than in those with both feet high-arched (right side: $p=0.01$; $\mathrm{ES}=1.25 ;-0.20 \pm 0.08 \mathrm{~Hz}$ vs. $-0.10 \pm 0.08 \mathrm{~Hz}$ ); (left side: $p=0.005$; ES $=1,17 ;-0.19 \pm 0.04 \mathrm{~Hz}$ vs. $-0.13 \pm 0.06 \mathrm{~Hz}$ ) and compared to those with normal feet arches (right side: $p=0.02$; ES $=0.58 ;-0.20 \pm 0.08 \mathrm{~Hz}$ vs. $-0.15 \pm 0.09 \mathrm{~Hz}$ ); (left side: $p=0.005 ; \mathrm{ES}=0.87 ;-0.19 \pm 0.04 \mathrm{~Hz}$ vs. $-0.14 \pm 0.07 \mathrm{~Hz}$ ). In the group with asymmetric foot arches, the frequency difference was significantly higher compared to those with both feet high-arched (right side: $p=0.01$; ES $=0.87 ;-15.4 \pm 6.8 \%$ vs. $10.4 \pm 4.3 \%$ ); (left side: $p=0.01$; ES $=0.96 ; 16.1 \pm 6.5 \%$ vs. $11.1 \pm 3.4 \%$ ). In the group with asymmetric foot arches, a significantly higher value of the masseter 
muscle frequency difference was observed on the high-arched side compared to the normal-arched side $(p=0.01 ; \mathrm{ES}=0.95 ; 6.91 \pm 4.1 \%$ vs. $3.62 \pm 2.8 \%)$. A little increase in the longitudinal arch of the foot, even though such is often not considered as pathological, may cause visible changes in muscle function, demonstrated as elevated signs of muscles fatigue. This study suggests that the consequences of foot high-arching may be present in distal body parts. Any alterations of the foot arch should be considered as a potential foot defect, and due to preventing muscle overloading, some corrective exercises or/and corrective insoles for shoes should be used. It can potentially reduce both foot overload and distant structures overload, which may diminish musculoskeletal system pain and dysfunctions.

Keywords: high-arched foot; muscle fatigue; sEMG; myofascial chains

\section{Introduction}

The skeletal muscles transmit force through a continuous network of connective tissues, according to a concept of force transmission [1-4]. The fascia is a connective tissue surrounding every structure in the human body [5]. Myofascial continuity (MC) was described as "the connection between two longitudinally adjacent and aligned structures within the fascia" [6-9]. This junction provides the ability to transfer tensegrity in the kinematic chain over greater distances than in the case of the musculotendinous system itself, acting locally $[7,10]$. The integrated concept of the kinetic chain suggests that muscle pathways are connected to each other and form a large network of myofascial chains, which may transfer force between its components [2,11-13]. The myofascial force transmission was suggested based on cadaveric research $[7,14]$ and in vivo studies $[15,16]$. Hyoung et al. [16] have reported that the restriction in ankle range of motion was probably affected by forward head posture. In different research by Hyoung et al. [15], it was shown that passive hamstring stretching influenced cervical spine range of motion. Some studies reported the relationship between body posture and temporomandibular dysfunctions and have suggested that alterations in head position and body posture may be influenced by inaccurate proprioceptive information from the masticatory system muscles [17-19]. Grieve et al. [20] showed that plantar fascia myofascial release increased sit-and-reach performance. Stecco et al. [7,14] demonstrated that muscle stretching caused force transmission through the fascia to the neighboring muscles. Because the foot arch is an elastic structure, it was reported that low arch is related to excessive foot pronation, while high arched foot is more rigid and inflexible [21]. Therefore, it is also probable that foot arch alterations may change force transfer via myofascial chains and may influence muscles located further away.

As it has been reported by some authors, foot posture abnormalities-flat and hollow foot-are very common developmental posture abnormalities noted among children, adolescents, and also among adults [22-26]. The foot arches are responsible for proper foot loading, optimal force distribution and transmission throughout the soft tissues. In a high-arched foot, the muscles of the lower leg, the short muscles of the foot and the plantar aponeurosis are overloaded [27,28]. Some authors have suggested that the changes in foot alignment may affect the proximal lower limbs and trunk muscles bioelectrical activity [29]. Therefore, all foot abnormalities, such as little elevations of the medial longitudinal arch above the norm, may affect its load distribution and force transmission along myofascial chains to the upper parts of the body [6,30-32]. Some authors have reported that muscle fatigue may change the compensatory contractions of the plantar flexor muscles as the corrective strategy provided in response to input from afferent pathways [33-36]. It has been noted that in the evaluation of muscle fatigue, small alterations in bioelectrical activity, assessed non-invasively via surface electromyography (sEMG), may be considered as a sensitive sign of muscle overloading [35,37]. The measurements of sEMG may be useful in muscle fatigue assessment during isometric and dynamic contractions [38,39]. 
It has been reported, in 80 percent of population rotated body patterns, what may increase the tension in specific body parts was observed, causing the body to be prone to asymmetry [32,40-42]. The asymmetry in the musculoskeletal system is widely considered as a strong factor of tissue overload and increased risk of injury [6,32,43]. It was reported that, in the tensegrity model, all asymmetrical tensions transmitted throughout musculofascial structures may lead to micro trauma, even in distant parts of the body, causing the decrease in muscle strength and endurance manifested as increased muscle fatigue $[14,32,40,44]$. Until now, no studies have reported the prevalence of asymmetrical foot arching in the general population, but occurrence of the asymmetry in musculoskeletal system has been described by many authors [32,40-42]. Thus, it is probable, that due to asymmetrical musculofascial tensions the asymmetry of foot arching occurs. Asymmetrical joint range of motion was linked with alterations in muscle and tendon length $[45,46]$, and it was indicated as a risk factor of musculoskeletal injury [43,47], just as the right/left feet arch height asymmetry. It has been reported that higher asymmetry in fatigue of erector spine muscle had been observed in subjects with low back pain than in healthy controls. The authors concluded that the higher asymmetry of erector spine muscle activity may indicate back muscle dysfunction [48]. Thus, we have hypothesized that only excessive arching of one foot may asymmetrically affect tension in some parts of the musculoskeletal chains, differently than when arches of both feet are excessive. As the foot is the part of all main myofascial chains (superficial front and back line, lateral, and the spiral), we have suggested that due to myofascial continuity, high arching of the feet may disrupt force transmission throughout the myofascial chains and may affect the upper parts of the body.

There are many studies in which the relationship between foot abnormalities and foot and lower leg muscle dysfunctions is described $[29,46]$. However, the studies, which report the influence of excessive foot arching on muscle function and evaluate the influence of asymmetric foot arching on the body proximal parts, are lacking. In the present study, this problem was undertaken for the first time. The objective of this study was to examine the effect of symmetrical and asymmetrical excessive feet arching on muscle fatigue in the lower limbs, trunk, and head.

\section{Materials and Methods}

\subsection{Participants}

In this study, 77 women (25.15 \pm 5.97 years old, body mass $62 \pm 10 \mathrm{~kg}$, body height $167 \pm 4 \mathrm{~cm}$, BMI $22.29 \pm 3.71$ ) were evaluated (Figure 1). They were at good health and did not have any orthopedic or neurological disorders.

Inclusion criteria:

- $\quad$ age between $20-40$ years

- $\quad$ average physical activity

- consent to participate in research

Exclusion criteria were:

- $\quad$ orthopedic disorders, which, by pain and movement restrictions, may significantly influence the study results, e.g., scoliosis, low back pain, lower limbs joints osteoarthrosis, knee ligaments rupture.

- neurological disorders, which may influence tests performance

- $\quad$ regular professional athletic training

- $\quad$ the acute injury during last 6-months before the study

- $\quad$ no consent to participate in research

According to foot arch index (AI) subjects were divided into 3 groups: [49-51].

Group $1(\mathrm{n}=35)$-women with normal arch in both feet, $\mathrm{AI}=25 \% \pm 1.4 \%$

$\mathrm{R}$-right side, L-left side

Group 2 ( $\mathrm{n}=23$ ) - women with asymmetrically arched feet (one foot with normal arch, $\mathrm{AI}=23.4 \% \pm 1.3 \%$ and the other high-arched, $\mathrm{AI}=15.8 \% \pm 1.5 \%$ ) 
$\mathrm{R}$-right side (in group 2-normally arched foot), L-left side (in group 2-high arched foot)

Group $3(\mathrm{n}=19)$-women with high-arch in both feet, $\mathrm{AI}=14 \% \pm 2.8 \%$

$\mathrm{R}$-right side, L-left side

All measurements were performed at one visit by experienced researchers, who were blinded to the subject group allocation. This study had cross-sectional design. The participants were detailedly informed about the study protocol and signed informed consent to participate in the study. All procedures were performed in accordance with the 1964 Helsinki declaration and its later amendments. The Bioethics Committee at the Regional Medical Association in Krakow (No 28/KBL/OIL/2018) approved the study.

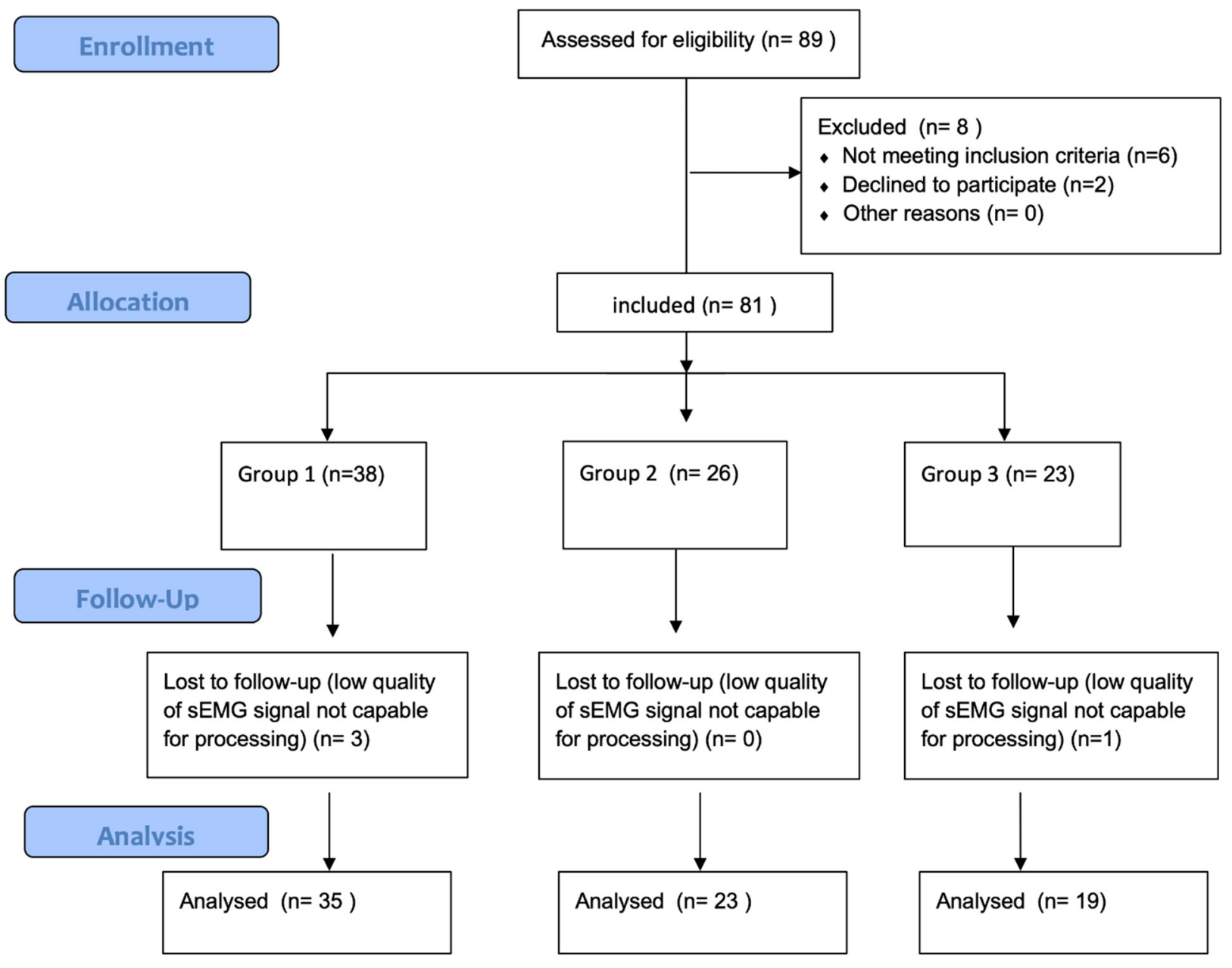

Figure 1. Study flow diagram.

\subsection{Experimental Procedures}

2.2.1. Arch Index Measurement

Plantar pressure distribution was assessed on the BTS P-WALK platform (BTS, Bioengineering, Italy) and then, the arch index was calculated using G-Studio software (BTS, Bioengineering, Italy). Prior to data collection, the platform was calibrated. Arch Index was measured barefoot, in a habitual, relaxed, position, standing for $30 \mathrm{~s}$ in the middle of the platform. It was calculated according to previously described formula (46) (Figure 2).

Arch Index (\%)—normal foot (18-30\%), high-arched foot $(<18 \%)$ [49-51]. 


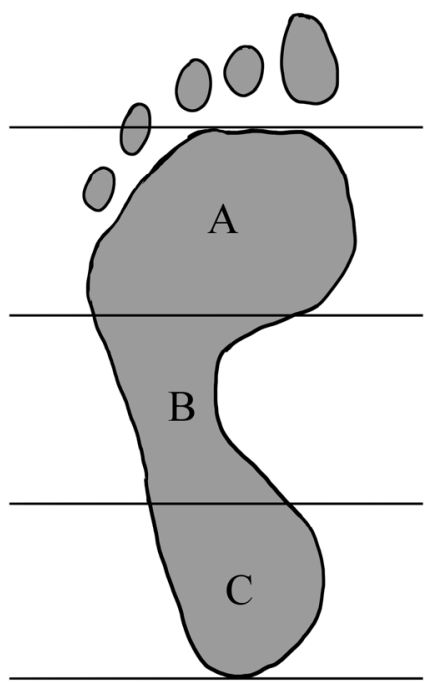

Figure 2. The arch index (AI) is calculated as the ratio of the midfoot area (B) to the area of the entire foot, excluding the toes $(\mathrm{A}+\mathrm{B}+\mathrm{C}) ; \mathrm{AI}=\mathrm{B} /(\mathrm{A}+\mathrm{B}+\mathrm{C})$.

\subsection{2. sEMG Measurement}

The bioelectrical activity of the right and left:

1. Lateral (biceps femoris-BF) and medial (semitendinosus and semimembranosusSEM) hamstring muscles

2. Erector spine muscle at lumbar (LUM) and at thoracic (TH) region

3. Masseter (MASS) and temporalis anterior (TA) muscles were measured according to the SENIAM guidelines [35,36,52]. Surface electrodes $(\mathrm{Ag} / \mathrm{AgCl})$ (Sorimex, Poland) with a $2 \mathrm{~cm}$ center-to-center distance after cleaning the skin with alcohol were attached on the muscles (Figure 3). The sEMG signals were recorded with 16-bit accuracy at a sampling rate of $1500 \mathrm{~Hz}$ with the Noraxon G2 TeleMyo 2400 unit (Noraxon USA).

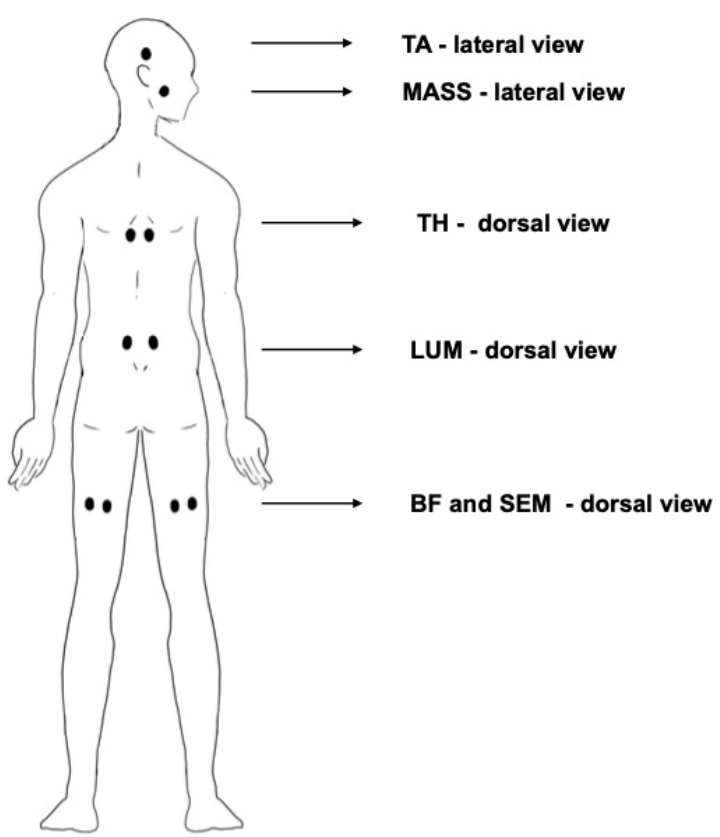

Figure 3. Placement of the electrodes on the subject's body during the test. BF-biceps femoris muscle. SEM - semitendinosus and semimembranosus hamstring muscles. LUM-erector spinae muscle at lumbar region. TH-erector spinae muscle at thoracic region. MASS-masseter muscle. TA-temporalis anterior muscle. 
The sEMG signal for all evaluated muscles was measured during $60 \mathrm{~s}$ of isometric contraction (Figure 4). The magnitude of the muscle isometric contraction was stable during all measurement. The visual feedback was provided on computer monitor, where the EMG signal was real-time visible. The measurements were performed in the following positions:

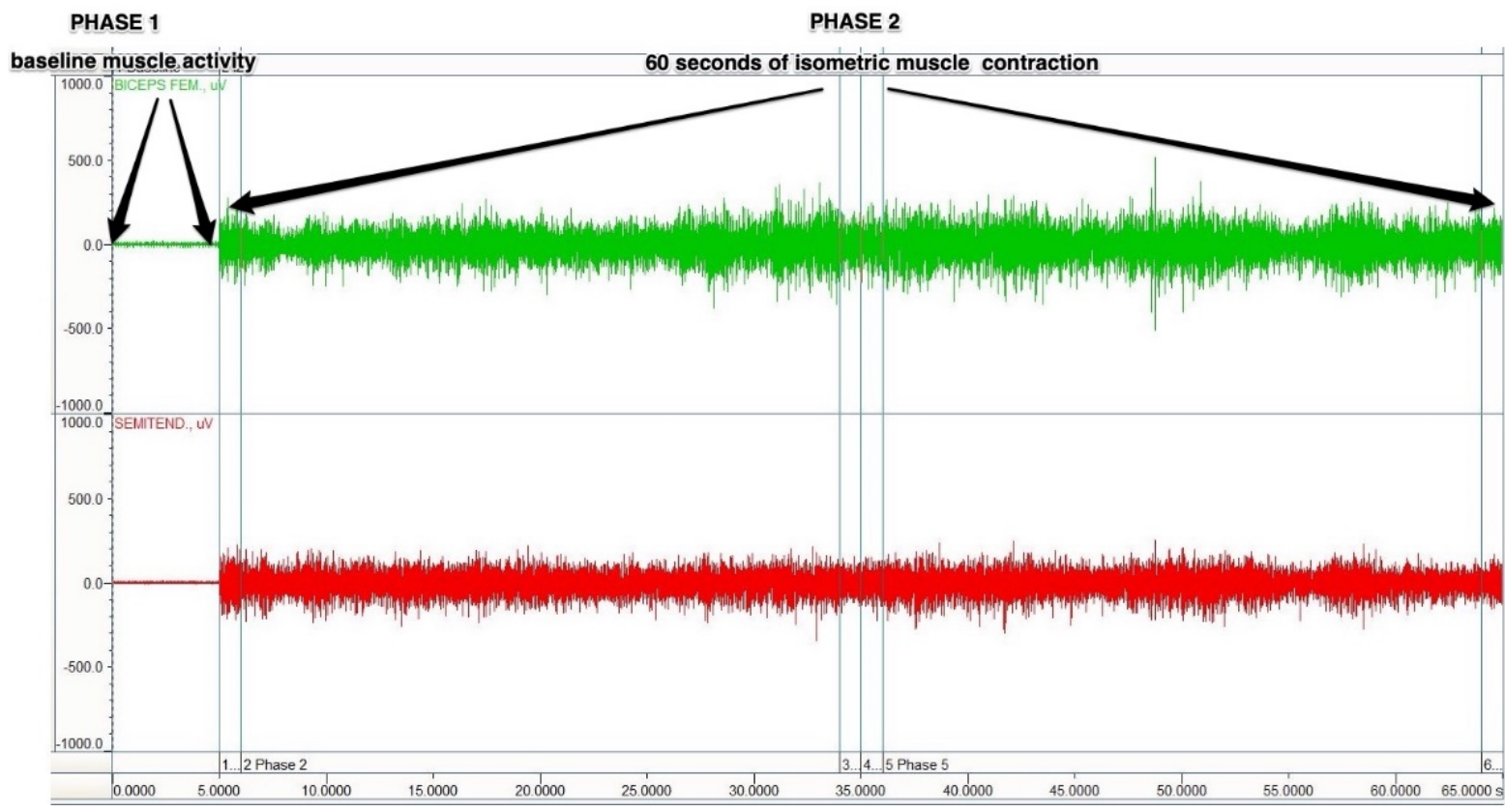

Figure 4. A schematic figure of the sEMG protocol.

1. Biceps femoris (BF) and semitendinosus-semimembranosus (SEM) muscles-Prone position, with the knee flexed to 60 degrees against manually applied resistance; (approximately $50 \%$ of maximal effort). Before starting the sEMG signal recording, the subject was asked to flex the evaluated leg against resistance applied by the researcher. The signal from the muscle was, at all times, seen on the computer screen. During the 5-10 s, the researcher adjusted the amount of resistance to the capabilities of the examined person, so the resistance was not too high and allows them to maintain a stable isometric contraction.

2. Lumbar (LUM) and thoracic (TH) erector spinae muscles-prone position, with the trunk raised without any additional resistance;

3. Masseter (MASS) and temporalis anterior (TA) muscles-sitting position, clenching of the teeth, with a cotton swab placed between the molar teeth; subjects were given a command: "clench the teeth as tight as you can".

Fatigue related changes, as mean frequency shifts, were calculated using the FFT (Fast Fourier Transform) processing method [52-54]. The raw sEMG signal was filtered using Low and High band pass filters to remove any artifacts below $10 \mathrm{~Hz}$ and above $500 \mathrm{~Hz}$. Then, the filtered signal was analyzed step-wise in $1 \mathrm{~s}$ intervals over 60-s isometrics contraction. Mean frequency was calculated for each step, and then, linear regression was computed with slope $(\mathrm{Hz})$ and intercept $(\mathrm{Hz})$ values. The slope was the steepness of the regression line, and the intercept was the place the line crosses the $y$-axis. The difference (\%) was calculated as the difference between the average mean frequencies from the first $3 \mathrm{~s}$ and last $3 \mathrm{~s}$.

\subsection{Statistical Analysis}

STATISTICA 12.0 software was used for analysis. The data were evaluated for normality with a Shapiro-Wilk test. One-way analysis of variance (ANOVA) was performed to assess the differences of the measurement variables across three study groups with Tukey's post-hoc test. Cohen's $d$ analysis was used for effect size calculation. The significance level 
was set at $(p<0.05)$. Paired $t$-test power analysis determined that 20 subjects in each group were required to obtain a power of 0.8 at a two-sided level of 0.05 , with the effect size of $\mathrm{d}=0.8$.

\section{Results}

\subsection{Fatigue of the Biceps Femoris (BF) and Semimembranosus-Semitendinosus (SEM) Muscles}

There were no differences in fatigue variables for the BF and SEM muscles between the right and left side in groups 1 and 3 (in women with symmetrical foot arches). However, in group 2 (with asymmetric foot arches), percent difference of the SEM muscle, on the side with the normal-arch foot, was significantly greater compared to the side with the high-arched foot. Significantly greater values of frequency differences were observed on the normal-arched side compared to the high-arched side. There were no significant differences between the study groups in BF and SEM muscle fatigue variables (Table 1).

\subsection{Fatigue of the Lumbar (LUM) and Thoracic (TH) Erector Spinae Muscles}

In the group 2 (with asymmetric foot arches), a significantly higher value of lumbar erector spinae muscle (LUM) fatigue was observed on the high-arched foot side compared to the side with normal foot arching. Significantly higher values of frequency slope and frequency difference were observed on the high-arched side compared to the normalarched side.

There were no differences between the right and left side in fatigue variables of the LUM muscle in groups 1 and 3 (women with symmetrical foot arches). There were also no differences in LUM muscle fatigue between study groups. The fatigue of thoracic erector spinae muscle (TH) did not vary between the left and right sides in any of the groups. However, the TH muscle fatigue was significantly larger in women with asymmetrical arches than in those with both feet high-arched, as well as compared to those with normal feet arches. In group 2, both the frequency slope and frequency differences were significantly higher, with high effect size indicating higher TH muscle fatigue, compared to groups 1 and 3. There were no differences in TH muscle fatigue variables between groups 1 and 3 (Table 2).

\subsection{Fatigue of the Masseter (MASS) and Temporalis Anterior (TA) Muscles}

In group 2 (with asymmetric foot arches), a significantly higher value of the MASS muscle fatigue was observed on the side with high-arched foot, compared to the side with normal foot arching. Significantly higher values of frequency differences were observed on the high-arched side compared to the normal-arched side. For frequency slope, higher values on the high-arched side were noted. However, this was not significant, but a tendency with the high effect size $(\mathrm{ES}=0.55)$ was observed. There were no significant differences between the right and left side in fatigue variables of the MASS muscle in groups 1 and 3 (in women with symmetrical foot arches), nor were there any significant differences between the study groups in MASS muscle fatigue variables. No differences in TA muscles fatigue variables were observed between the left and right sides in all groups and between study groups (Table 3). 
Table 1. Comparison of biceps femoris (BF) and semimembranosus-semitendinosus (SEM) muscles fatigue variables between study groups.

\begin{tabular}{|c|c|c|c|c|c|c|c|c|c|c|c|c|c|c|}
\hline Outcome Measure & Side & Group 1 & $p \#$ & Group 2 & $p \#$ & Group 3 & $p \#$ & $p$ & $p^{*}$ & ES & $p^{* *}$ & ES & $p^{* * *}$ & ES \\
\hline \multirow{2}{*}{ BF slope $(\mathrm{Hz})$} & $\mathrm{R}$ & $-0.13 \pm 0.15(0.02)$ & \multirow[b]{2}{*}{0.76} & $-0.21 \pm 0.18(0.04)$ & \multirow[b]{2}{*}{0.16} & $-0.13 \pm 0.18(0.04)$ & \multirow[b]{2}{*}{0.29} & 0.22 & 0.31 & 0.48 & 0.99 & 0.01 & 0.37 & 0.44 \\
\hline & $\mathrm{L}$ & $-0.14 \pm 0.10(0.02)$ & & $-0.13 \pm 0.11(0.03)$ & & $-0.17 \pm 0.09(0.03)$ & & 0.57 & 0.98 & 0.09 & 0.63 & 0.31 & 0.72 & 0.39 \\
\hline \multirow{2}{*}{ BF Intercept (Hz) } & $\mathrm{R}$ & $59.9 \pm 11.2(1.8)$ & \multirow{2}{*}{0.07} & $65.8 \pm 13.1(2.80)$ & $0<0$ & $61.1 \pm 9.6(2.26)$ & \multirow{2}{*}{0.14} & 0.16 & 0.20 & 0.48 & 0.94 & 0.11 & 0.44 & 0.40 \\
\hline & $\mathrm{L}$ & $65.7 \pm 15.2(2.58)$ & & $64.4 \pm 13.3(2.85)$ & 0.69 & $64.9 \pm 13.1(3.55)$ & & 0.94 & 0.95 & 0.45 & 0.98 & 0.05 & 0.99 & 0.03 \\
\hline \multirow{2}{*}{ BF difference (\%) } & $\mathrm{R}$ & $-20.2 \pm 11.3(1.91)$ & \multirow{2}{*}{0.34} & $-22.4 \pm 14.4(3.08)$ & & $-19.2 \pm 12.5(2.96)$ & \multirow[b]{2}{*}{0.43} & 0.71 & 0.83 & 0.21 & 0.97 & 0.08 & 0.73 & 0.23 \\
\hline & $\mathrm{L}$ & $-17.6 \pm 13.2(2.23)$ & & $-21.1 \pm 13.4(2.86)$ & 0.76 & $-15.8 \pm 11.4(2.71)$ & & 0.52 & 0.72 & 0.26 & 0.93 & 0.14 & 0.54 & 0.42 \\
\hline \multirow{2}{*}{ SEM slope (Hz) } & $\mathrm{R}$ & $-0.20 \pm 0.09(0.01)$ & \multirow{2}{*}{0.47} & $-0.25 \pm 0.10(0.02)$ & & $-0.20 \pm 0.11(0.02)$ & \multirow{2}{*}{0.41} & 0.14 & 0.23 & 0.52 & 0.99 & 0.01 & 0.26 & 0.47 \\
\hline & $\mathrm{L}$ & $-0.22 \pm 0.12(0.02)$ & & $-0.22 \pm 0.13(0.02)$ & 0.23 & $-0.22 \pm 0.09(0.02)$ & & 0.96 & 0.98 & 0.01 & 0.97 & 0.01 & 0.99 & 0.01 \\
\hline \multirow{2}{*}{ SEM Intercept $(\mathrm{Hz})$} & $\mathrm{R}$ & $56.6 \pm 6.8(1.15)$ & \multirow{2}{*}{0.69} & $56.8 \pm 7.6(1.63)$ & (1) & $55.5 \pm 9.1(2.15)$ & \multirow{2}{*}{0.44} & 0.84 & 0.99 & 0.02 & 0.89 & 0.13 & 0.86 & 0.15 \\
\hline & $\mathrm{L}$ & $57.1 \pm 5.9(1.01)$ & & $60.2 \pm 9.9(2.53)$ & 0.14 & $54.4 \pm 7.1(1.68)$ & & 0.09 & 0.62 & 0.38 & 0.41 & 0.41 & 0.10 & 0.67 \\
\hline \multirow{2}{*}{ SEM difference (\%) } & $\mathrm{R}$ & $-25.2 \pm 8.9(1.51)$ & \multirow{2}{*}{0.61} & $-29.5 \pm 9.1(1.92)$ & $p=0.04$ & $-24.2 \pm 10.1(2.38)$ & \multirow{2}{*}{0.25} & 0.13 & 0.27 & 0.47 & 0.94 & 0.10 & 0.20 & 0.55 \\
\hline & $\mathrm{L}$ & $-24.3 \pm 10.1(1.69)$ & & $-24.9 \pm 8.4(2.50)$ & $\mathrm{ES}=0.52$ & $-27.0 \pm 12.2$ & & 0.70 & 0.98 & 0.06 & 0.74 & 0.24 & 0.83 & 0.20 \\
\hline
\end{tabular}

$p \#-p$ value between right and left side within each group; $p$-ANOVA study groups main effect; $p^{*}-p$ value between group 1 and group 2 (the $p$ value there is the post-hoc of study groups main effect); $p^{* *}-p$ value between group 1 and group 3 (the $p$ value, there, is the post-hoc of study groups main effect); $p^{* * *}-p$ value between group 2 and group 3 (the $p$ value, there, is the post-hoc of study groups main effect); ES — effect size (Cohen d); R-right side (in group 2—normally arched foot); L-left side (in group 2-high arched foot); Values are expressed as Mean \pm SD (SEM); SD—Standard Deviation; SEM—Standard Error of Measurement.

Table 2. Comparison of lumbar (LUM) and thoracic (TH) erector spinae muscles fatigue variables between study groups.

\begin{tabular}{|c|c|c|c|c|c|c|c|c|c|c|c|c|c|c|}
\hline Outcome Measure & Side & Group 1 & $p \#$ & Group 2 & $p \#$ & Group 3 & $p \#$ & $p$ & $p^{*}$ & ES & $p^{* *}$ & ES & $p^{* * *}$ & ES \\
\hline \multirow{2}{*}{ LUM slope $(\mathrm{Hz})$} & $\mathrm{R}$ & $-0.16 \pm 0.08(0.01)$ & \multirow{2}{*}{0.13} & $-0.14 \pm 0.05(0.03)$ & $p=0.01$ & $-0.13 \pm 0.08(0.01)$ & \multirow{2}{*}{0.43} & 0.75 & 0.89 & 0.29 & 0.80 & 0.35 & 0.97 & 0.14 \\
\hline & $\mathrm{L}$ & $-0.14 \pm 0.07(0.01)$ & & $-0.20 \pm 0.04(0.03)$ & $\mathrm{ES}=1.32$ & $-0.12 \pm 0.07(0.01)$ & & 0.09 & 0.27 & 1.05 & 0.83 & 0.28 & 0.12 & 1.40 \\
\hline \multirow{2}{*}{ LUM Intercept $(\mathrm{Hz})$} & $\mathrm{R}$ & $78.3 \pm 9.6(1.63)$ & \multirow[b]{2}{*}{0.15} & $82.7 \pm 10.9(2.28)$ & & $84.5 \pm 13.5(3.10)$ & \multirow[b]{2}{*}{0.33} & 0.11 & 0.37 & 0.42 & 0.19 & 0.52 & 0.86 & 0.14 \\
\hline & $\mathrm{L}$ & $75.6 \pm 10.7(1.81)$ & & $81.0 \pm 11.9(2.48)$ & 0.55 & $81.9 \pm 13.1(3.04)$ & & 0.10 & 0.26 & 0.47 & 0.22 & 0.52 & 0.96 & 0.10 \\
\hline LUM difference (\%) & $\mathrm{L}$ & $-11.4 \pm 6.1(1.04)$ & 0.63 & $-7.8 \pm 3.1(1.87)$ & $\mathrm{ES}=0.92$ & $-6.1 \pm 4.6(1.29)$ & 0.50 & 0.12 & 0.42 & 0.74 & 0.21 & 0.98 & 0.85 & 0.43 \\
\hline \multirow{2}{*}{ TH slope $(\mathrm{Hz})$} & $\mathrm{R}$ & $-0.15 \pm 0.09(0.01)$ & \multirow{2}{*}{0.73} & $-0.20 \pm 0.08(0.02)$ & & $-0.10 \pm 0.08(0.01)$ & \multirow{2}{*}{0.17} & 0.005 & 0.02 & 0.58 & 0.26 & 0.58 & 0.01 & 1.25 \\
\hline & $\mathrm{L}$ & $-0.14 \pm 0.07(0.01)$ & & $-0.19 \pm 0.04(0.02)$ & 0.73 & $-0.13 \pm 0.06(0.01)$ & & 0.02 & 0.005 & 0.87 & 0.75 & 0.15 & 0.005 & 1.17 \\
\hline \multirow{2}{*}{ TH Intercept (Hz) } & $\mathrm{R}$ & $66.4 \pm 12.7(2.15)$ & \multirow{2}{*}{0.23} & $68.3 \pm 12.1(2.53)$ & 067 & $65.3 \pm 12.9(2.96)$ & \multirow{2}{*}{0.75} & 0.72 & 0.85 & 0.15 & 0.96 & 0.08 & 0.74 & 0.23 \\
\hline & $\mathrm{L}$ & $68.5 \pm 13.9(2.35)$ & & $67.2 \pm 14.6(3.05)$ & $0.6 \%$ & $66.1 \pm 11.8(2.72)$ & & 0.82 & 0.94 & 0.09 & 0.85 & 0.18 & 0.96 & 0.08 \\
\hline TH difference $(\%)$ & $\mathrm{L}$ & $-12.7 \pm 6.4(1.09)$ & 0.34 & $-16.1 \pm 6.5(2.31)$ & 0.68 & $-11.1 \pm 3.4(0.78)$ & 0.66 & 0.03 & 0.28 & 0.51 & 0.78 & 0.30 & 0.01 & 0.96 \\
\hline
\end{tabular}

$p \# \_p$ value between right and left side within each group; $p$-ANOVA study groups main effect; $p^{*} — p$ value between group 1 and group 2 (the $p$ value, there, is the post-hoc of study groups main effect); $p^{* *}-p$ value between group 1 and group 3 (the $p$ value, there, is the post-hoc of study groups main effect); $p^{* * *}-p$ value between group 2 and group 3 (the $p$ value, there, is the post-hoc of study groups main effect); ES — effect size (Cohen d); R-right side (in group 2-normally arched foot); L-left side (in group 2-high arched foot); Values are expressed as Mean \pm SD (SEM); SD-Standard Deviation; SEM-Standard Error of Measurement. 
Table 3. Comparison of masseter (MASS) and temporalis anterior (TA) muscles fatigue variables between study groups.

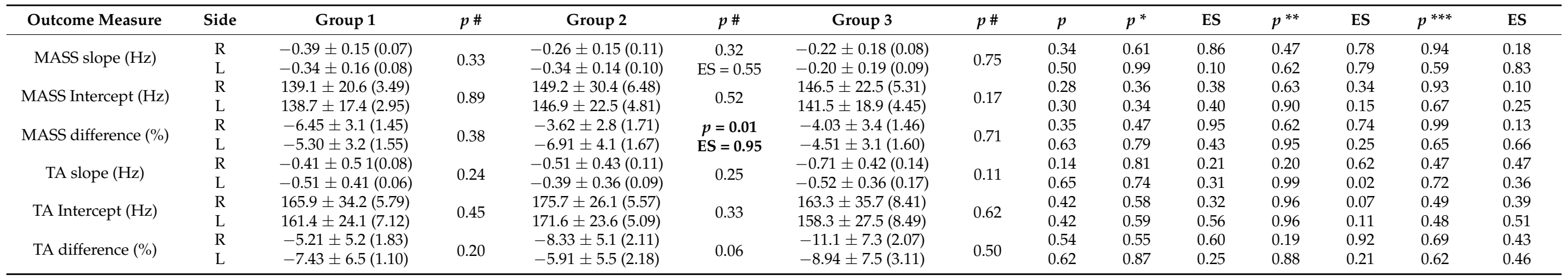

$p \# \_p$ value between right and left side within each group; $p$-ANOVA study groups main effect; $p^{*} \_p$ value between group 1 and group 2 (the $p$ value, there, is the post-hoc of study groups main effect); $p^{* *}-p$ value between group 1 and group 3 (the $p$ value, there, is the post-hoc of study groups main effect); $p^{* * *}-p$ value between group 2 and group 3 (the $p$ value there, is the post-hoc of study groups main effect); ES — effect size (Cohen d); R—right side (in group 2 - normally arched foot); L—left side (in group 2 - high arched foot); Values are expressed as Mean \pm SD (SEM); SD—Standard Deviation; SEM-Standard Error of Measurement. 


\section{Discussion}

In this study, we have observed that increases in the foot arch, even slight, which is usually not classified as pathological, may be related to visible changes in muscle function demonstrated as elevated signs of muscles fatigue. No significant differences were observed in fatigue variables for all evaluated muscles between the right and left side in women with symmetrical foot arches, but in the group with asymmetric foot arches, the higher muscle fatigue on one side was noted. Additionally, the TH muscle fatigue was significantly larger in women with asymmetrical arches than in those with both feet high-arched and those with normal feet arches.

Some authors have reported the relationship between altered neuromuscular control and muscle fatigue $[37,55,56]$. Some authors have suggested that alterations in soft tissues may lead to distant body part overloading and may create permanent changes in the ligament-fascial system $[27,47]$. Even low-level isometric muscle contraction may contribute to tissue stress [57,58].

Murley et al. [29] observed that changing the foot position by the orthosis may affect the bioelectric activity (sEMG) of the lower limb and trunk muscles, and they suggested that unnatural foot alignment may affect muscle tension in distant parts of the body. In our study, bilaterally increased feet arching did not cause significant differences in fatigue of the examined muscles compared to the subjects with bilaterally normal arches of the feet. However, asymmetrical feet high-arching caused increased muscle fatigue which, as we have hypothesized, may lead to following asymmetries in muscles, working within the myofascial chains. The authors suggest that these changes seem to be related to previously observed alterations in load distribution under the feet and changes in body posture [59].

It has been reported that plantar fascia dysfunctions may be associated with alterations in hamstring muscle strength and in changes of lumbar lordosis angle [6]. It has been suggested that reduced flexibility and tightness of the hamstring and calf muscles may lead to plantar fasciitis [57,58]. Marr et al. [60] have also reported a relationship between decreased hamstring muscle flexibility and lumbar spine dysfunctions. Weisman et al. [61] have reported a relationship in muscle activations along the superficial back line (SBL), applying passive and active range of motion with and without resistance. They observed that neck extension, with and without resistance, strongly influenced the extensor spine and hamstring muscle bioelectrical activity (sEMG) [61]. The results of their studies demonstrated that isolated movements may activate more than one muscle along the kinematic chain and, moreover, if the performed muscle activation is more forceful, greater activity was observed in other muscles of the chain. Those observations were confirmed by Kassolik et al. [13].

In the authors' study among women with asymmetric foot arches, the fatigue of SEM muscle on side with normal foot arching was significantly higher compared to the side with high-arched foot. In women with symmetrically arched feet (groups 1 and 3), no significant differences were observed between right and left leg muscle fatigue on both the lateral (BF) and medial sides (SEM). The authors have suggested that the observed differences in muscle bioelectrical activity may cause alterations in muscle tension throughout the myofascial chains. It is probable that asymmetrical limb loading may be associated with the development of adverse tensions within the myofascial system, which may lead to asymmetric tension in myofascial chains [62].

However, this seems to be related to previously observed changes in the load distribution of the feet and in body posture [59]. In a previous work among subjects with high-arched feet, the higher loading of the forefoot, with simultaneously decreased midfoot loading, was observed, while in the foot with proper arching, the load was evenly distributed. In women with one-sided high arch of the foot, asymmetrical limb loading was also observed, while more pressure was directed to the limb with the correct arch of the foot. Additionally, in case of asymmetric feet high-arching, the transfer of body mass to the normally arched foot relieves the high-arched foot, causing incorrect load distribution [59]. It may be assumed that the increased transfer of body mass to the normally-arched limb 
increases its load and probably causes greater fatigue of the hamstring muscle. Therefore, the muscles on the normally arched side had to work harder, which could have caused the higher fatigue. As was reported previously, the changes in time and frequency domain of the surface electromyogram are related to local muscle fatigue. An increase in the sEMG signal amplitude reflects additional recruited motor units during muscles contraction. The decrease in signal frequency indicated a decreased conduction velocity along the muscle fibers in the fatigued muscle $[63,64]$.

It was also observed that, in women with high arched feet, in addition to increased loading of the forefoot, reduced forward trunk inclination was also noted [59]. The authors have suggested that the reduction in trunk tilt may be a compensatory response to the increased load of the forefoot. The authors have hypothesized that increased fatigue of the thoracic extensor spine muscles may result from increased rectifying activity of the muscle in the thoracic region due to the need to keep the trunk tilted less forward which was observed. In addition, in women with unilaterally high-arched foot, significantly greater fatigue of the extensor spine muscle was observed in the lumbar region on the side with excessive arching. The increased lumbar muscle fatigue on one side only, may suggest the existence of altered force transmission via the myofascial chain, which may be related to both excessive foot arch and the difference in shoulder height observed in such women [59]. This may indicate that the existence of asymmetries within the trunk muscles may be associated with altered feet loading. This means that on the side of the excessively arched foot, this muscle gets tired faster.

The same situation was observed within the masseter muscles. In the group with asymmetrical feet arches, significantly greater fatigue was observed on the side with excessive arching. In this group, increased fatigue of the masseter on the excessively arched side may also be associated with the previously observed significant difference in shoulder height [59] and, as suggested in other studies, with alteration of foot arch [65]. Valentino et al. [65] studied young men, who had molar teeth pre-contact changes in sEMG activity of temporalis and masseter muscles due to placing some insoles under the plantar arch of the feet. They reported the dependence between the occlusal plane and the morphological changes of the plantar arch [65]. These authors, in their later study, reported evidence of functional correlations among masticatory muscles and alterations of the plantar arches, due to flat foot. They observed that the masticatory muscles undergo some functional changes and hypothesized that this occurred due to the fact that the mechanoreceptors in the tendons of the plantar arch muscles were stimulated in different ways, changing the activation of the whole myofascial chain [65]. They have demonstrated that functional connections are present between the occlusal plane and the plantar arches. Similar results have been obtained in the authors' study, in which the masseter muscle on the high-arched side was more fatigued than on the opposite side. In a different study on walking, Cuccia et al. [66] showed differences in plantar arches between subjects with and without temporomandibular joint disorders.

In previous studies, no possible association between foot arch alterations and muscles fatigue distant from the feet has been demonstrated. It has been suggested that dysfunction in any of the muscles along any kinematic chain may alternate activation patterns and augment myofascial pressure, especially in global body stabilizers [61]. In such situations, other muscles may compensate for the dysfunction, which finally overloads them, decreasing functional range of motion and inducing pain along more regions in the myofascial chains $[7,14,59]$. All of these findings strengthen the validity of the tensegrity model of force transmission, and they may help guide treatment strategies of patients suffering from musculoskeletal disorders.

This study also has some limitations. Due to methodological restrictions, muscle fatigue assessment was performed during isometric contraction, which means that these results should not be fully extrapolated into dynamic conditions. Moreover, further research covering other foot abnormalities may allow for better understanding of forces transmitted via myofascial chains from the foot to the distal body parts such as hip, pelvis, thorax, and 
head. Research with the larger group, which included both sexes, would be of interest. It should be also noted that frequency changes in different muscles may have different range and a different output value because each muscle has its own frequency specificity (e.g., depending on the proportion of slow and fast fibers). Therefore, it should be considered during the interpretation of sEMG signal frequency changes due to fatigue.

\section{Conclusions}

In this study, it has been shown that probably a little increase in the foot longitudinal arch, even though such is often not considered as pathological, may cause visible changes in muscle function demonstrated as elevated signs of muscles fatigue. The observed increase in fatigue of muscles distant from the foot may suggest that altered force transmission, due to slight elevation of the foot's longitudinal arch, may affect the muscles at the level of the thigh, pelvis, trunk, as well as the head. One-side foot high-arching may be related to increased fatigue of muscles on one side only, which may cause following tissues asymmetries. We have concluded that any alterations of the foot arch should be considered as a potential foot defect, and due to preventing muscle overloading, some corrective exercises or/and corrective insoles for shoes should be used. It can potentially reduce both foot overload and distant structures overload, which may diminish musculoskeletal system pain and dysfunctions.

Author Contributions: Conceptualization, R.W., Ł.O., A.J.-S., A.M., R.K. and A.S.; Methodology, R.W., Ł.O., A.J.-S., A.M., R.K. and A.S.; Software, R.W., Ł.O., A.M.; Formal Analysis, R.W., Ł.O., and A.M.; Investigation, R.W. and A.J.-S.; Resources, R.W., Ł.O. and A.M.; Data Curation, A.M.; Writing-Original Draft Preparation, R.W. and A.M.; Writing-Review \& Editing, Ł.O., A.J.-S., R.K. and A.S.; Supervision, R.W. and A.M.; Project Administration, A.M. and R.W. All authors have read and agreed to the published version of the manuscript.

Funding: This study was performed within the framework of the program of the Minister of Science and Higher Education under the name 'Regional Initiative for Perfection' within the years 2019-2022, project No. 022/RID/2018/19, supported by the National Science Centre in Poland.

Institutional Review Board Statement: Not applicable.

Informed Consent Statement: Not applicable.

Data Availability Statement: All data generated or analyzed during this study are included in this article.

Conflicts of Interest: The authors declare no conflict of interest.

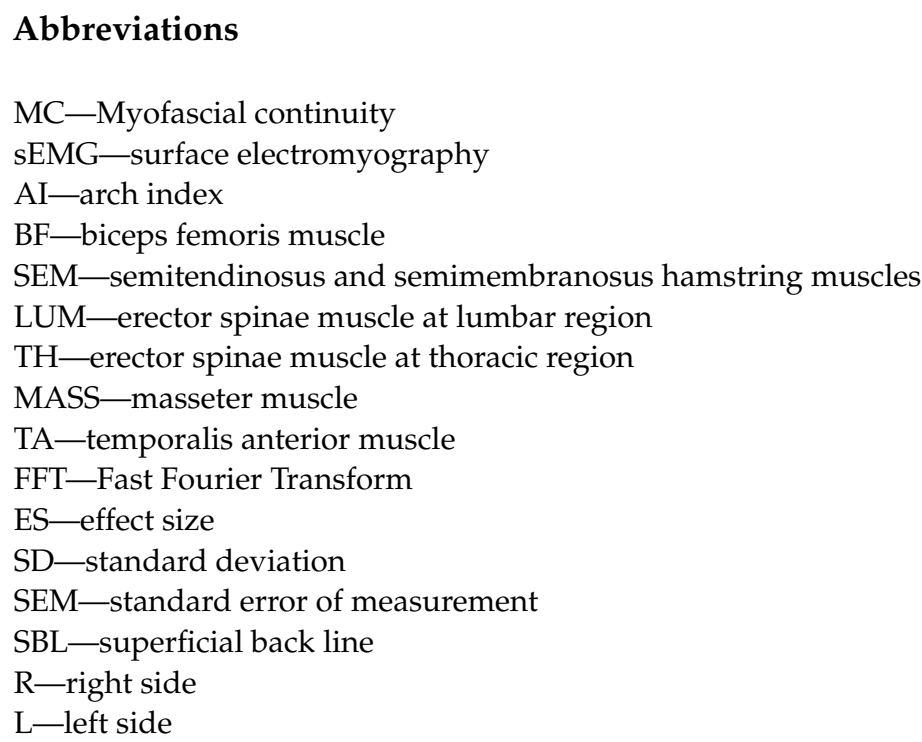




\section{References}

1. Bernabei, M.; Maas, H.; van Dieën, J.H. A lumped stiffness model of intermuscular and extramuscular myofascial pathways of force transmission. Biomech. Modeling Mechanobiol. 2016, 15, 1747-1763. [CrossRef]

2. Stecco, C.; Porzionato, A.; Macchi, V.; Stecco, A.; Vigato, E.; Parenti, A.; Delmas, V.; Aldegheri, R.; De Caro, R. The expansions of the pectoral girdle muscles onto the brachial fascia: Morphological aspects and spatial disposition. Cells Tissues Organs 2008, 188, 320-329. [CrossRef]

3. Huijing, P.A. Epimuscular myofascial force transmission: A historical review and implications for new research. International Society of Biomechanics Muybridge Award Lecture, Taipei, 2007. J. Biomech. 2009, 42, 9-21. [CrossRef] [PubMed]

4. Maas, H.; Sandercock, T.G. Force transmission between synergistic skeletal muscles through connective tissue linkages. J. Biomed. Biotechnol. 2010, 2010, 575-672. [CrossRef]

5. Schleip, R.; Klingler, W.; Lehmann-Horn, F. Active fascial contractility: Fascia may be able to contract in a smooth muscle-like manner and thereby influence musculoskeletal dynamics. Med. Hypotheses 2005, 65, 273-277. [CrossRef] [PubMed]

6. Myers, T. Anatomy Trains: Myofascial Meridians for Manual and Movement Therapists, 3rd ed.; Elsevier: Amsterdam, The Netherlands; Churchill Livingstone: London, UK, 2014.

7. Stecco, A.; Macchi, V.; Stecco, C.; Porzionato, A.; Day, J.A.; Delmas, V.; De Caro, R. Affiliations expand Anatomical study of myofascial continuity in the anterior region of the upper limb. J. Bodyw. Mov. 2009, 13, 53-62. [CrossRef] [PubMed]

8. Turvey, M.T.; Fonseca, S.T. The medium of haptic perception: A tensegrity hypothesis. J. Mot. Behav. 2014, 46, 143-187. [CrossRef] [PubMed]

9. Krause, F.; Wilke, J.; Vogt, L.; Banzer, W. Intermuscular force transmission along myofascial chains: A systematic review. J. Anat. 2016, 228, 910-918. [CrossRef]

10. Masi, A.T.; Hannon, J.C. Human resting muscle tone (HRMT): Narrative introduction and modern concepts. J. Bodyw. Mov. Ther 2008, 12, 320-332. [CrossRef]

11. Dischiavi, S.L.; Wright, A.A.; Hegedus, E.J.; Bleakley, C.M. Biotensegrity and myofascial chains: A global approach to an integrated kinetic chain. Med. Hypotheses 2018, 110, 90-96. [CrossRef]

12. Langevin, H. Connective tissue: A body-wide signaling network? Med. Hypotheses 2006, 66, 1074-1077. [CrossRef]

13. Kassolik, K.; Jaskólska, A.; Kisiel-Sajewicz, K.; Marusiak, J.; Kawczyński, A.; Jaskólski, A. Tensegrity principle in massage demonstrated by electro- and mechanomyography. J. Bodyw. Mov. Ther. 2009, 13, 164-170. [CrossRef] [PubMed]

14. Stecco, C.; Porzionato, A.; Lancerotto, L.; Stecco, A.; Macchi, V.; Day, J.A.; De Caro, R. Histological study of the deep fasciae of the limbs. J. Bodyw. Mov.Ther. 2008, 12, 225-230. [CrossRef] [PubMed]

15. Hyong, I.H.; Kang, J.H. The immediate effects of passive hamstring stretching exercises on the cervical spine range of motion and balance. J. Phys. Ther. Sci. 2013, 25, 113-116. [CrossRef]

16. Hyong, I.H.; Kim, J.H. The effect of forward head on ankle joint range of motion and static balance. J. Phys. Ther. Sci. 2012, 24, 925-927. [CrossRef]

17. Nicolakis, P.; Nicolakis, M.; Piehslinger, E.; Ebenbichler, G.; Vachuda, M.; Kirtley, C.; Fialka-Moser, V. Relationship between craniomandibular disorders and poor posture. Cranio 2000, 18, 106-112. [CrossRef] [PubMed]

18. Cuccia, A.; Caradonna, C. The relationship between the stomatognathic system and body posture. Clinics 2009, 64, 61-66. [CrossRef] [PubMed]

19. Evcik, D.; Aksoy, O. Correlation of temporomandibular joint pathologies, neck pain and postural differences. J. Phys. Ther. Sci. 2000, 12, 97-100. [CrossRef]

20. Grieve, R.; Goodwin, F.; Alfaki, M.; Bourton, A.J.; Jeffries, C.; Scott, H. The immediate effect of bilateral self-myofascial release on the plantar surface of the feet on hamstring and lumbar spine flexibility: A pilot randomized controlled trial. J. Bodyw. Mov. Ther. 2015, 19, 544-552. [CrossRef]

21. Aminian, A.; Sangeorzan, B.J. The anatomy of cavus foot deformity. Foot Ankle Clin. 2008, 13, 191-198. [CrossRef]

22. Rao, U.B.; Joseph, B. The influence of footwear on the prevalence of flat foot. J. Bone Ankle Surg. 1992, 74, 525-527. [CrossRef]

23. Stavlas, P.; Grivas, T.B.; Michas, C.; Vasiliadis, E.; Polyzois, V. The evolution of foot morphology in children between 6 and 17 years of age: A cross-sectional study based on footprints in a Mediterranean population. J. Foot Ankle Surg. 2005, 44, 424-428. [CrossRef]

24. Umbrasko, S.; Vetra, J.; Dulevska, J.; Boka, S.; Gavricenkova, L.; Zagare, R. Specifiers of foot growth among schoolchildren of Riga and Latvian regions. Pap. Anthropol. 2007, 16, 283-292.

25. Woźniacka, R.; Bac, A.; Matusik, S.; Szczygieł, E.; Ciszek, E. Body weight and the medial longitudinal food arch: High arched foot, a hidden problem? Eur. J. Pediatr. 2013, 172, 683-691. [CrossRef] [PubMed]

26. Woźniacka, R.; Bac, A.; Matusik, S. Effect of obesity level on the longitudinal arch in 7- to 12-year-old rural and urban children. J. Am. Podiatr. Med. Assoc. 2015, 105, 484-492. [CrossRef] [PubMed]

27. Buldt, A.K.; Forghany, S.; Landorf, K.B.; Levinger, P.; Murley, G.S.; Menz, H.B. Foot posture is associated with plantar pressure during gait: A comparison of normal, planus and cavus feet. Gait Posture 2018, 62, 235-240. [CrossRef]

28. Burns, J.; Crosbie, J.; Hunt, A.; Ouvrier, R. The effect of pes cavus on foot pain and plantar pressure. Clin. Biomech. (Bristol Avon) 2005, 20, 877-882. [CrossRef] [PubMed]

29. Murley, G.S.; Landorf, K.B.; Menz, H.B.; Ouvrier, R. Effect of foot posture, foot orthoses and footwear on lower limb muscle activity during walking and running: A systematic review. Gait Posture 2009, 29, 172-187. [CrossRef] 
30. Levin, D.; Whittle, M.W. The effects of pelvic movement on lumbar lordosis in the standing position. J. Orthop. Sports Phys. Ther. 1996, 24, 130-135. [CrossRef]

31. Duval, K.; Lam, T.; Sanderson, D. The mechanical relationship between the rearfoot, pelvis and low-back. Gait Posture 2010, 32, 637-640. [CrossRef]

32. Morris, C.E.; Bonnefin, D.; Darvillem, C. The Torsional Upper Crossed Syndrome: A multi-planar update to Janda's model, with a case series introduction of the mid-pectoral fascial lesion as an associated etiological factor. J. Bodyw. Mov. Ther. 2015, 19, 681-689. [CrossRef]

33. Forestier, N.; Teasdale, N.; Nougier, V. Alteration of the position sense at the ankle induced by muscular fatigue in humans. Med. Sci. Sports Exerc. 2002, 34, 117-122. [CrossRef]

34. Gimmon, Y.; Riemer, R.; Oddsson, L.; Melzer, I. The effect of plantar flexor muscle fatigue on postural control. J. Electromyogr. Kinesiol. 2011, 21, 922-928. [CrossRef]

35. Merletti, R.; Parker, P. Electromyography: Physiology, Engineering, and Non-Invasive Applications; Wiley-IEEE Press: Hoboken, NJ, USA, 2004.

36. Hermens, H.J.; Freriks, B.; Merletti, R. SENIAM 8: European Recommendations for Surface Electromyography; Roessingh Research and Development: Enschede, The Netherlands, 1999.

37. Kasman, G.S.; Cram, J.R.; Wolf, S.L. Clinical Applications in Surface Electromyography, Chronic Musculoskeletal Pain; Aspen Publishers: Gaithersburg, MD, USA, 1998.

38. Gonzalez-Izal, M.; Malanda, A.; Gorostiaga, E.; Izquierdo, M. Electromyographic models to assess muscle fatigue. J. Electromyogr. Kinesiol. 2012, 22, 501-512. [CrossRef] [PubMed]

39. Gazzoni, M.; Botter, A.; Vieira, T. Surface EMG and muscle fatigue: Multi-channel approaches to the study of myoelectric manifestations of muscle fatigue. Physiol. Meas. 2017, 38, 27-60.

40. Pope, R.E. The common compensatory pattern: Its origin and relationship to the postural model. Am. Acad. Osteopathy J. 2003, 14, 19-40.

41. Tozzi, P. Selected fascial aspects of osteopathic practice. J. Bodyw. Mov. Ther. 2012, 16, 503-519. [CrossRef] [PubMed]

42. Kouwenhoven, J.W.M.; Vincken, K.L.; Bartels, L.W.; Casteleine, R.M. Analysis of preexistent vertebral rotation in the normal spine. Spine 2006, 31, 1467-1472. [CrossRef] [PubMed]

43. Hodges, P.W.; Cholewicki, J. Functional Control of the Spine. In Movement, Stability E Lumbopelvic Pain: Integration of Research and Therapy; Vleeming, A., Mooney, V., Stoeckart, R., Eds.; Churchill Livingstone: London, UK; Elsevier: Amsterdam, The Netherlands, 2007.

44. Rolf, I.P.; Feitis, R. Rolfing and Physical Reality; Inner Traditions/Bear \& Co: Rochester, VT, USA, 1990.

45. Bendová, P.; Růzicka, P.; Peterová, V.; Fricová, M.; Springrová, I. MRI-based registration of pelvic alignment affected by altered pelvic floor muscle characteristics. Clin. Biomech. 2007, 22, 980-987. [CrossRef]

46. Snijders, C.J.; Vleeming, A.; Stoeckart, R. Transfer of lumbosacral load to iliac bones and legs. Part 1, 2. Clin. Biomech. 1993, 8, 295-301. [CrossRef]

47. Resende, R.A.; Deluzio, K.J.; Kirkwood, R.N.; Hassan, E.A. Increased unilateral foot pronation affects lower limbs and pelvic biomechanics during walking. Gait Posture 2015, 41, 395-401. [CrossRef]

48. Hao, Z.; Xie, L.; Wang, J.; Hou, Z. Spatial Distribution and Asymmetry of Surface Electromyography on Lumbar Muscles of Soldiers with Chronic Low Back Pain. Pain Res. Manag. 2020, 26. [CrossRef] [PubMed]

49. Cavanagh, P.R.; Rodgers, M.M. The arch index: A useful measure from footprints. J. Biomech. 1987, 20, 547-551. [CrossRef]

50. Murley, G.S.; Menz, H.B.; Landorf, K.B. A protocol for classifying normal- and flat-arched foot posture for research studies using clinical and radiographic measurements. J. Foot Ankle Res. 2009, 4, 2-22. [CrossRef] [PubMed]

51. Wong, C.K.; Weil, R.; de Boer, E. Standardizing foot-type classification using arch index values. Physiother. Can. 2012, 64, 280-283. [CrossRef] [PubMed]

52. Hermens, H.J.; Freriks, B.; Disselhorst-Klug, C.; Rau, G. Development of recommendations for SEMG sensors and sensor placement procedures. J. Electromyogr. Kinesiol. 2000, 10, 361-374. [CrossRef]

53. Cifrek, M.; Medved, V.; Tonković, S.; Ostojić, S. Surface EMG based muscle fatigue evaluation in biomechanics. Clin. Biomech. 2009, 24, 327-340. [CrossRef] [PubMed]

54. Coorevits, P.; Danneels, L.; Cambier, D.; Ramon, H.; Druyts, H.; Karlsson, J.S.; De Moor, G.; Vanderstraeten, G. Correlations between short-time Fourier- and continuous wavelet transforms in the analysis of localized back and hip muscle fatigue during isometric contractions. J. Electromyogr. Kinesiol. 2008, 18, 637-644. [CrossRef]

55. Coorevits, P.; Danneels, L.; Cambier, D.; Ramon, H.; Druyts, H.; Karlsson, J.S.; De Moor, G.; Vanderstraeten, G. Test-retest reliability of wavelet and Fourier based EMG (instantaneous) median frequencies in the evaluation of back and hip muscle fatigue during isometric back extensions. J. Electromyogr. Kinesiol. 2008, 18, 798-806. [CrossRef]

56. Gribble, P.A.; Hertel, J. Effect of hip and ankle muscle fatigue on unipedal postural control. J. Electromyogr. Kinesiol. 2004, 14, 641-646. [CrossRef]

57. Mueller, M.J.; Maluf, K.S. Tissue adaptation to physical stress: A proposed "Physical Stress Theory" to guide physical therapist practice, education, and research. Phys. Ther. 2002, 82, 383-403. [CrossRef] [PubMed]

58. Bolívar, Y.A.; Munuera, P.V.; Padillo, J.P. Relationship between tightness of the posterior muscles of the lower limb and plantar fasciitis. Foot Ankle Int. 2013, 34, 42-48. [CrossRef] [PubMed] 
59. Woźniacka, R.; Oleksy, Ł.; Jankowicz-Szymańska, A.; Mika, A.; Kielnar, R.; Stolarczyk, A. The association between high-arched feet, plantar pressure distribution and body posture in young women. Sci. Rep. 2019, 9, 17187. [CrossRef] [PubMed]

60. Marr, M.; Baker, J.; Lambon, N.; Perry, J. The effects of the Bowen technique on hamstring flexibility over time: A randomized controlled trial. J. Body Mov. Ther. 2011, 15, 281-290. [CrossRef] [PubMed]

61. Weisman, M.H.; Haddad, M.; Lavi, N.; Vulfsons, S. Surface electromyography recordings after passive and active motion along the posterior myofascial kinematic chain in healthy male subjects. J. Bodyw. Mov. Ther. 2014, 18, 452-461. [CrossRef]

62. Betsch, M.; Schneppendahl, J.; Dor, L.; Jungbluth, P.; Grassmann, J.P.; Windolf, J. Influence of foot position on the spine and pelvis. Arthritis Care Res. 2011, 63, 1758-1765. [CrossRef]

63. Søgaard, K.; Blangsted, A.K.; Jørgensen, L.V.; Madeleine, P.; Sjøgaard, G. Evidence of long term muscle fatigue following prolonged intermittent contractions based on mechano- and electromyograms. J. Electromyogr. Kinesiol. 2003, 13, 441-450. [CrossRef]

64. Rudroff, T.; Staudenmann, D.; Enoka, R.M. Electromyographic measures of muscle activation and changes in muscle architecture of human elbow flexors during fatiguing contractions. J. Appl. Physiol. (1985) 2008, 104, 1720-1726. [CrossRef]

65. Valentino, B.; Fabozzo, A.; Melito, F. The functional relationship between the occlusal plane and the plantar arches. An EMG study. Surg. Radiol. Anat. 1991, 13, 171-174. [CrossRef]

66. Cuccia, A.M. Interrelationships between dental occlusion and plantar arch. J. Body Mov. Ther. 2011, 15, 242-250. [CrossRef] 